\title{
An analysis of the physical condition of two intensively grazed Southland soils
}

\author{
P.R. GREENWOOD and R.M. McNAMARA \\ AgResearch, Invermay Agricultural Centre, Private Bag 50034, Mosgiel
}

\begin{abstract}
The treading effects of high-density winter grazing of sheep associated with all-grass wintering systems in Southland were studied for evidence of resultant soil physical degradation. Typical examples of Pukemutu (YGE) and Waikiwi (YBE) soils, extensive areas of which have been intensively managed in Southland for many years, were selected for assessments of mechanical impedance, bulk density, porosity, air permeability, and hydraulic conductivity. The results showed that intensive winter grazing in this environment resulted in significant losses of large soil macropores. As a result, the transmission of water through the root-zone was significantly restricted. After rain, this can lead to waterlogging and soil oxygen deficiencies. Probably as a result of cumulative soil damage over several winters, soil had become more compacted to nearly the full depth of the A horizon. Natural ameliorative processes may therefore be too slow to overcome fully the effects of treading. Measurements of mechanical impedance and bulk density, while widely used, proved inappropriate for examination of the effects of treading. Both are insensitive to small, but important, changes in soil porosity. Air permeability and hydraulic conductivity were good indicators of relative degrees of soil compactness of the sites examined. Both are sensitive to small changes in effective macroporosity, and are useful measurements to diagnose soil structural damage.
\end{abstract}

Keywords all-grass wintering, Southland, sheep, treading damage, soil physical degradation

\section{Introduction}

Soil physical degradation is of major international concern as it can severely limit the productivity of agricultural land. In particular. the importance of soil compaction associated with arable farming has long beenrecognised and is the subject of many reviews. Through adverse effects on soil Porosity and mechanical impedance, compaction can reduce the transmission of water and air, and restrict root growth (Greenwood \& Cameron 1990). Such effects often substantially reduce plant yield.
Compared with traffic compaction in arable systems, the compaction of pastoral soils by animal treading has received much less attention, but has nonetheless been reported as a significant process in the physical deterioration of agricultural soils (e.g. Gradwell 1960; Gifford \& Hawkins 1978).

In the all-grass sheep wintering system which has developed in Otago and Southland, stocking densities are very high in winter when soils are wet and most susceptible tocompaction. There is widespreadconcern that the compactive stresses being imposed on the soil by such a system has resulted in significant physical degradation of pastoral soils. The effects of heavy winter treadiig in these regions therefore warrants research.

This paper reports some results of a study conducted to compare the physical properties of two Southland soils with histories of high and low winter stocking densities.

\section{Methods}

Two Southland soils with contrasting natural drainage status were selected for study during the springs of 1990 and 1991; Pukemutu silt loam and Waikiwi silt loam.

The Pukemutu silt loam is a yellow-grey earth derived from greywacke loess overlying weathered alluvium (Bruce 1984). It covers approximately 19000 ha of terraces in central Southland under a rainfall of approximately $850-1000 \mathrm{~mm}$. Theprofileisdominated by a compact clay loam subsoil which restricts water transmission. Mole and tile drainage systems are widely used to improve drainage but, nonetheless, this soil is frequently very wet during the autumn, winter and spring seasons.

The Waikiwi silt loam is a yellow-brown earth which covers approximately 50000 ha of the Southland Plains under an annual rainfall of $1000-1300 \mathrm{~mm}$. It is derived from greywacke loess overlying weathered gravels. The silt to clay loam subsoil is less compact than the Pukemutu subsoil, and is therefore well drained in comparison. Very wet conditions therefore occur less frequently in the Waikiwi soil.

For each soil, three farm properties were selected which contained typical examples of areas subjected to intensive and to lax grazing with sheep. On each property, two paddocks were chosen for sampling. One 
of those had a long history of high density winter grazing (800-2000 sheep/ha for 1-3 days each winter), while the other had not been intensively stocked during winter. On the Pukemutu soil, the three properties were located near Wmton and on the Waikiwi soil they were near Woodlands.

In each of the 12 paddocks chosen, soil penetration resistance was measured with a cone penetrometer (1 .0 $\mathrm{cm}^{2}, 30^{\circ}$ cone) at $5 \mathrm{~cm}$ increments to $50 \mathrm{cmdepth}$. It was measured at 30 positions along a $100 \mathrm{~m}$ transect. Soil water content was measured at the same time.

Undisturbed soil cores $(75 \mathrm{~mm}$ and $100 \mathrm{~mm}$ diameter) were carefully taken from the $\mathbf{0}-\mathbf{2}, \mathbf{0}-\mathbf{5}, \mathbf{5}-\mathbf{1 0}, \mathbf{1 7}-\mathbf{1 9}$, and 34-36 cm soil depths for assessments of pore size distribution and bulk density. Larger cores (103 mm and 150 mm diameter) were collected from the $0-5,5-10,10$. 20 , and $20-30 \mathrm{~cm}$ depths for measurements of air permeability and both saturated and unsaturated hydraulic conductivity. For each soil depth, cores were sampled in triplicate from each site.

\section{Results and discussion}

Penetrometers are often used to characterise the influence of animal treading on soil mechanical impedance and hence compactness. Often, the data obtained clearly show the compactive result of treading (e.g. Kelly 1985). In the current study. however, no such result is evident for the Waikiwi soil, and differences between lax and intensive grazing on the Pukemutu soil were minor (Figure 1). Furthermore, the latter differences may be largely accounted for by differences in soil watercontentbetween treatments (Figure 1) as thenegative influence of soil water content on penetration resistance can be substantial (Cassel1982).

It is therefore necessary to measure resistance at a standard value of soil water. In practice. however, standardisation of the field water contents to within narrow

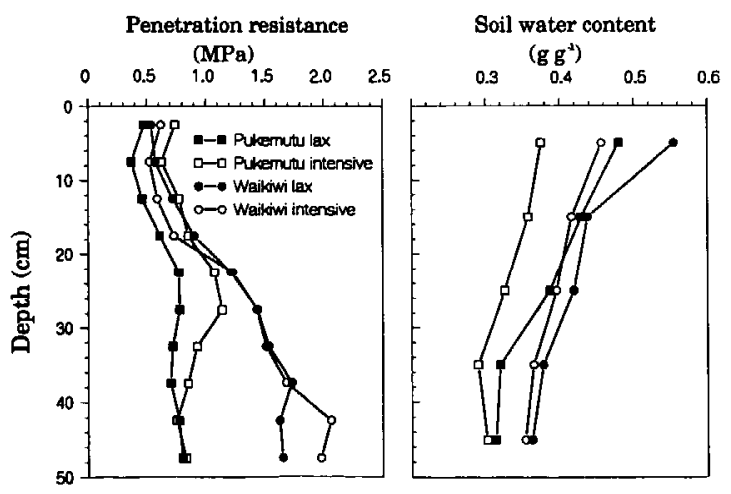

Figure 1 Penetration rasistance and soil water contcnt for Pukcmutu and Waiki wi soils under $l a x$ and intensive winter grazing management. None of the differences are statistically significant $(P<0.05)$. limits is nearly impossible to achieve

Because of its simplicity, bulk density is the most commonly measured soil physical property in treading studies. In common with a number of such studies both in NZ and overseas (e.g. Gradwell 1968; Kelly 1985) intensive grazing of the two Southland soils increased bulk densities only slightly (Figure 2). However, bulk density measurements are insensitive to small changes in soil compactness, and often do not relate well to plant or other soil physical responses to compaction (Greenwood \& Cameron 1990). Furthermore, in Southland where soil watercontents areoftenhighforlongperiods, poor soil aeration is more likely to be of greater practical significance than is restricted root extension caused by a zone of dense soil. Indeed, it is widely acknowledged that extensive root systems are unnecessary in moist conditions (Kramer 1983).

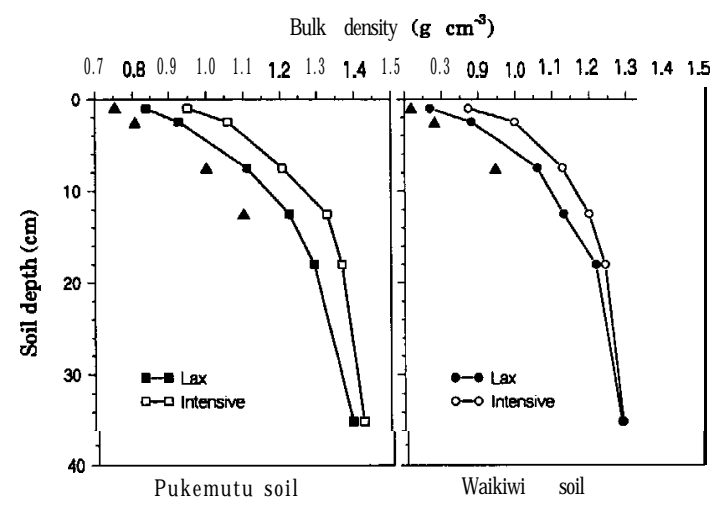

Figure 2 Soil dry bulk density. $\Delta$ denoteg significant difference (P<0.05) between lax and intensive means $\mathrm{al}$ the same soil depth

Macropores conduct most of the water through a soil during wet conditions, thus macroporosity is a more appropriate measure of the compacting effects of treading in Southland than is bulk density which, like penetration resistance, is insensitive to small numbers of these pores. Values of macroporosity in both of the Southland soils studied were lowest where there was a history of high-density winter grazing (Figure 3). However, only in the Pukemutu soil were macroporosities reduced to less than $10 \%$ of total soil volume; a value often regarded as defining critical conditions of aeration (Gradwell 1968; Cannel1 1977). The macroporosity results also suggest that the Pukemutu soil was compacted to a greater depth; i.e. $20 \mathrm{~cm}$ compared with $10-15 \mathrm{~cm}$ for the Waikiwi soil.

Pore continuity is an important aspect of the functional effectiveness of macropores (Taylor \& Ashcroft 1972). and in the transmission of water, is regarded as more important than macropore volume alone (Ball et al. 1988). Air permeability is a sensitive indicator of the 


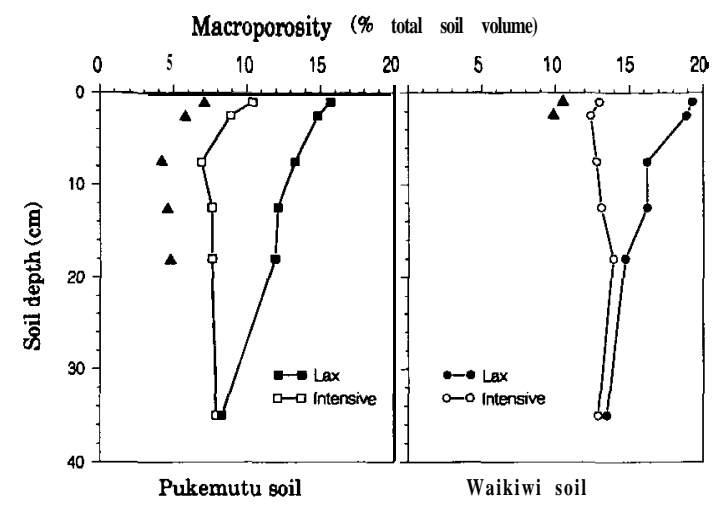

Figure 3 Soil macroporosity (volume of soil pores larger than 30 rm diameter).

presence of large continuous soil pores (Greenwood \& Cameron 1990). and in this study was markedly reduced by intensive winter grazing (Figure 4).

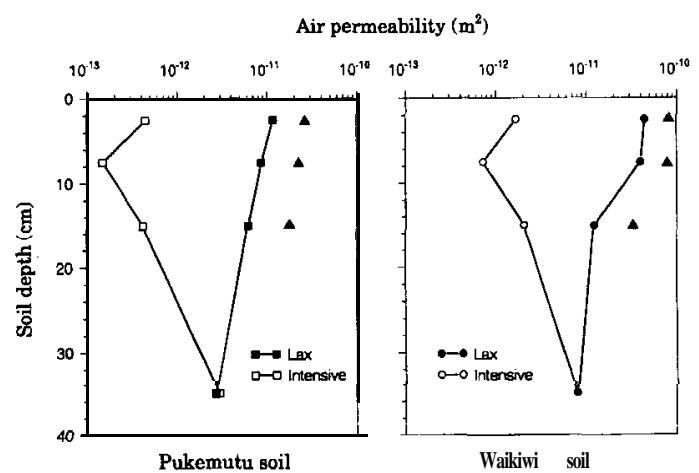

Figure 4 Geometric means of air permeability.

In both Southland soils, air permeabilities of the 0 $10 \mathrm{~cm}$ soil depth were more than an order of magnitude lower under intensive than under lax management. The magnitude of reduction at this depth was similar for both soils. However, at the $10-20 \mathrm{~cm}$ depth, it appeared that air permeability was reduced to a greater extent in the Pukemutu soil than in the Waikiwi soil. Nonetheless, the effect of intensive stocking was statistically significant at that depth for both soils.

Clearly, intensive winter grazing in the Southland environment has had a significant compacting effect on both soils. However, structural degradation to nearly the full depth of the A horizon (the top $20-25 \mathrm{~cm}$ of soil) was unexpected as. in earlier studies, the effects of sheep treading generally penetrated to less than $7.5 \mathrm{~cm}$ depth. Where deeper effects have been reported, they were mostly the result of treading by cattle (e.g. Kelly 1985; Mulholland \& Fullen 1991) which impose higher hoof pressures on the soil surface (Willat \& Pullar 1983). Compared with sheep grazing densities imposed in earlier studies, however, those typical of high density wintering systems in Southland are much higher (8002000 compared with 10-100 sheep/ha).

The ability of a soil to withstand compaction is inversely related to soil water content Consequently. wetter soils compact and deform more readily. In common with previous studies (Gifford \& Hawkins 1978). intensive treading, by decreasing effective macroporosity, significantly reduced hydraulic conductivity (Figure 5). Drainage of excess water following rainfall would therefore have been restricted after treading, resulting in wetter topsoils and increased susceptibility to further treading for prolonged periods. The deep influence of intensive treading in Southland may, therefore, be the result of increasingly severe and cumulative effects of successive compactions over the 10 years or more that such intensive winter management has been practised in the region. It appears that any natural regeneration of soil structure by wetting and drying cycles. or by root and earthworm activity, has been too slow to counter such cumulative degradation.

In a similar manner, the difference in natural drainage status between the poorly drained Pukemutu and the better-drained Waikiwi soils may explain the seemingly greater susceptibility of the former soil to damage.

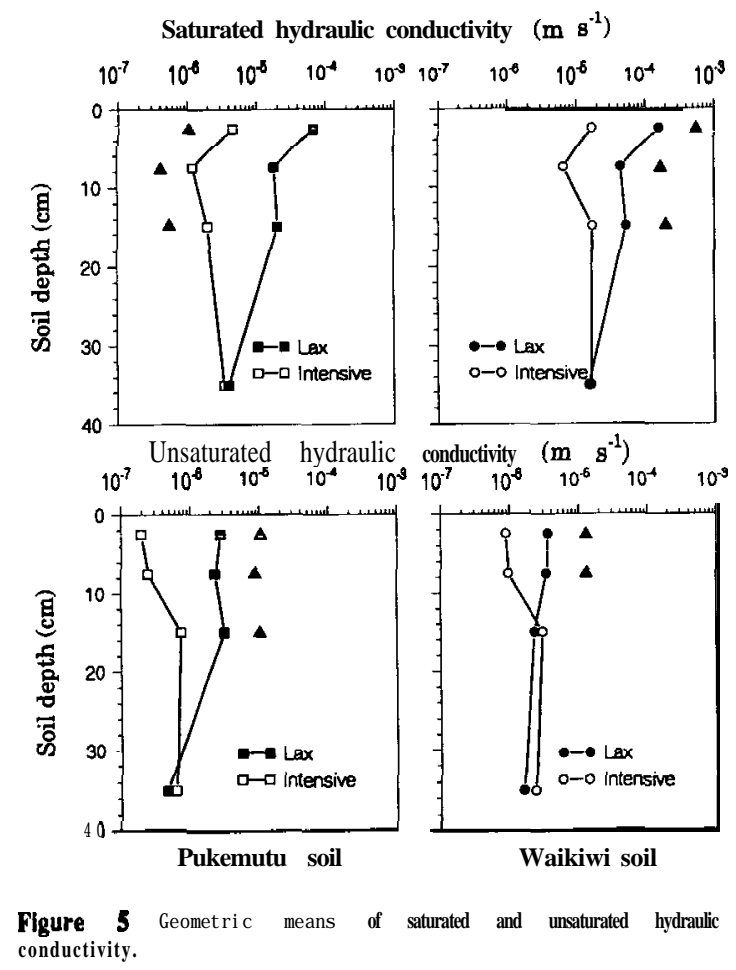


Although that difference in susceptibility appears evident in the macroporosity, air permeability, and saturated hydraulic conductivity results, it seems more marked withunsaturated hydraulic conductivity (Figure 5). During the latter measurement, soil pores larger than $300 \mathrm{pm}$ diameter are excluded from the flow process. Water transmission through smaller macropores (i.e. 30-300 pm diameter) was reduced by treading to a much greater extent in the Pukemutu soil than in the Waikiwi soil. Because increasing severity of compaction affects progressively smaller macropores, such a result confii that the Pukemutu soil suffered the greatest damage by treading.

Using hydraulic conductivity data (Figure 5), estimates of densities of large functional macropores indicate that in the Waikiwi soil, $\mathbf{7 0 - 8 0 \%}$ of such pores were lost from the topsoil by treading. For the Pukemutu soil the corresponding loss was approximately $95 \%$. Such a loss of large macropores in both soils is likely to have important consequences as those pores are the major pathways for water and air transmission. In this work, $8598 \%$ of total water transmission occurred in pores of the size largely lost by intensive treading.

Because the presence of water-filled pores is the main restriction to soil aeration (Cannel1 1977). reduced drainage of the topsoil caused by treading damage may create oxygen deficiencies in the root zone after rainfall. These conditions restrict root growth and activity and therefore the uptake of water and nutrients. Together with other chemical changes, especially the loss of soluble nitrate by denitrification, conditions of poor aeration may significantly reduce pasture production. Indeed. such an effect has previously been reported as a result of treading damage (Gradwell 1965).

For the Southland environment, however, the effects of soil physical degradation resulting from intensive treading. as reported in this paper, are largely unknown. Consequently, studies are now underway to examine, in detail, the effects of intensive treading on soil and plant factors, and to investigate the improvement of degraded soils by natural and mechanical processes and by modified stock management practices. A major survey is also being conducted to assess the extent of treading damage in Otago and Southland.

\section{Conclusions}

In Southland, winter treading by sheep at stocking densities typical of the all-grass wintering systems employed there (800-2000 sheep/ha) can result in significant soil physical degradation. By reducing hydraulically effective soil macroporosity, treading damage restricts the transmission of water through the topsoil. an effect which can lead to waterlogging and root-zone oxygen deficiencies after rain. Soil structural deteriora- tion can occur to nearly the full depth of the A horizon, probably as a result of cumulative damage over several winters. This indicates that natural ameliorative processes are too slow to fully overcome the effects of treading.

Further work is required to assess the extent of such soil degradation. to quantify effects on pasture production, and to investigate means of overcoming treading damage.

\section{ACKNOWLEDGEMENTS}

We thank J.S. Scandrett for valuable assistance, F.G. Beccroft for help in site selection, P.D. Johnstone for statistical advice, and R.J.W. Campbell, J.B. Hargest, J.A. Clark, P. King, T. Broad for allowing sampling of their land.

\section{REFERENCES}

Ball, B.C.; O'Sullivan, M.F.; Hunter, R. 1988. Gas diffusion, fluid flow and derived pore continuity indices in relation to vehicle traffic and tillage. Journal of Soil Science 39: 327-339.

Bruce, J.G. 1984. Soil resources of the Southland region, New Zealand. NZ Soil Bureau, Soil Survey Report 76.

Cannell, R.Q. 1977. Soil aeration and compaction in relation to root growth and soil management. Applied Biology 2: 1-86.

Cassel, D.K. 1982. Tillage effects on soil bulk density and mechanical impedance, p. 45-67. In: Unger. P.W.; et al., editors. Predicting tillage effectsonsoil physical principles and processes. American Society of Agricultural Engineers. Special Publication no. 44, ASAE-SSSA, Madison, Wisconsin.

Gifford, G.F.; Hawkins. R.H. 1978. Hydrologic impact of grazing on infiltration: a critical review. Water Resources Research 14: 305-313.

Gradwell, M.W. 1960. Changes in the pore-space of a pasture topsoil under animal treading. N.Z. Journal of Agricultural Research 3: 663-674.

Gradwell. M.W. 1965. Soil physical conditions of winter and the growth of ryegrass plants. I. effects of compaction and puddling. NZ Journal of Agricultural Research 8: 238-269.

Gradwell, M.W. 1968. Compaction of pasture topsoils under wintergrazing.p.428-435. In:Tansactions of the 9th International Cong ress of Soil Science. Adelaide Australia.

Greenwood, P.B.; Cameron, K.C. 1990. Subsoiling research in North Otago and Canterbury: an overview. In: Proceedings of the 5th national Land Drainage Conference. Massey. NZ 
Kelly, K.B. 1985. Effects of soil modification and treading on pasture growth and physical properties of an irrigated red-brown earth. Australian Journal of Agricultural Research 36: 799-807.

Kramer, P.J. 1983. Water relations of plants. Academic Press, New York.

Taylor, S.A.; Ashcroft, G.L. 1972. Physical edaphology. Thephysicsof irrigated and nonirrigated soils. W.H. Freeman and Company, San Francisco.

Willatt, S.T.; Pullar, D.M. 1983. Changes in soil physical properties under grazed pasture. Australian Journal of Soil Research 22: 343-348. 